\title{
Sealing Ability of Resin Based Root Canal Sealers: An In Vitro Study
}

\author{
Rijal $\mathbf{S}^{*}$ \\ 'Assistant Professor \\ Gandaki Medical College, College of Dental Sciences, Pokhara, Nepal
}

\section{Keywords \\ Coronal sealing, Dentine, Obturation, Root canal, Sealer. \\ Corresponding author Dr. Sujan Rijal, BDS, MDS. Assistant Professor, Gandaki Medical College \& Teaching Hospital, Pokhara, Nepal Email:drsujanrijal@gmail.com}

\begin{abstract}
The primary goal is to attain a three dimensional seal, which would lead to an impervious seal. Obturation of the prepared root canal eliminates all avenues of leakage from the oral cavity and the periodontal tissues, sealing any residual irritants that remain within the root canal system after cleaning and shaping. Though the primary goal of obturation has been clearly defined there is still an ongoing research for a sealer and a core material that would provide an apical as well as coronal seal.
\end{abstract}

\section{INTRODUCTION}

A complete three dimensional impervious obturation of the root canal system is of prime clinical importance for the long-term success of endodontic treatment ${ }^{1,2}$. Although a number of materials are used for obturation, the most common material is combination of guttapercha cones and sealer. As gutta-percha does not bond to root canal walls, the use of sealers along with welladapted gutta-percha has been recommended. To date, a great variety of endodontic materials are introduced to the dental community.

It appears that a root canal filling containing gutta-percha is the weak point in endodontic therapy. Filling of the root canal with gutta-percha and sealer even by the most technically proficient operator will not result in a seal that is dependable. Many different materials have been proposed as root canal fillings, but none have replaced gutta-percha which is universally accepted as the gold standard filling material. Manufacturers have made attempts to develop new products having better physical properties than the commonly used materials. The search of a material which would bond the root dentin and posses the properties of a root canal filling material was required.

Epiphany (Pentron Clinical Technologies, Wallingford, CT) and Real Seal (Sybron Endo, Orange, CA) sealers have similar chemical composition with different brand names and are designed for bonding simultaneously to intra-radicular dentin ${ }^{3}$. Real Seal exhibited rheological properties suitable for clinical use and defined as a dental resin composite material. There are just a handful of published literatures on long-term evaluations of Real $\mathrm{Seal}^{4}$. Studies have reported that the sealing ability of gutta percha / epiphany combinations is superior to that 
of the gutta-percha / AH plus combinations ${ }^{5-7}$

Failure of root-canal treatment can be attributed to a number of causes, but leakage through the root filling itself is thought to be a major factor. Strindberg, in 1956, considered that the most common cause of failure was leakage of tissue fluids apically around inadequate root fillings.

Endodontic leakage research focused mainly on the quality of the apical seal of the root canal system. Coronal leakage of the root canal filled tooth is an important cause in the failure of the root canal treatment. Several studies have shown that root canal fillings are susceptible to leakage when contaminated coronally by artificial saliva and microorganisms ${ }^{9-11}$.

\section{OBJECTIVES}

The aim of the study was to evaluate the coronal sealing ability of a new obturating sealer; GP/ Real Seal SE sealer and compare it with GP / AH plus sealer by evaluating

1. Sealability of GP / Real Seal SE sealer with coronal radicular dentin by linear dye leakage.

2. Comparing the coronal linear dye penetration in between GP / Real Seal SE sealer and GP / AH plus at various moisture conditions

\section{METHODS}

Thirty extracted human teeth with type 1 canal anatomy were selected. The length of all specimens was standardized by sectioning the roots at $17 \mathrm{~mm}$ from the apex with the high speed airotor hand piece. The instrumentation was done by RaCe instruments as per the manufacturer's instruction for anterior teeth. After final instrumentation all teeth received a final irrigation of 15 $\mathrm{ml} 1.25 \%$ sodium hypochlorite and $5 \mathrm{ml}$ 17\% EDTA. The canals were finally flushed with $10 \mathrm{ml}$ saline to remove any remaining sodium hypochlorite.

The teeth were divided into six groups of five teeth each. Specimens were subjected to three different moisture conditions and were obturated using GP / Real Seal SE sealer and GP / AH plus sealer and Sealer as per their groups

\section{Canals dried with ethanol}

Group 1 (GP + AH Plus sealer $)$

Group 4 (GP + Real Seal SE sealer)

\section{Canals dried with paper points}

Group 2 (GP + AH plus sealer)

Group 5 (GP + Real Seal SE sealer)

\section{Moist canals}

Group 3 (GP + ZnOE sealer)

Group 6 (GP + Real Seal SE sealer)

The specimens were immersed in a $2 \%$ methylene blue dye solution ( $\mathrm{pH} 7.4$ ) for 7 days at $37^{\circ} \mathrm{C}$ after removal and then they were rinsed with distilled water and stored at $37^{\circ} \mathrm{C}$ and $100 \%$ relative humidity. After removing from the dye solution, the specimens were thoroughly washed with water and dried and were examined under the light microscope. The linear dye penetration from the coronal to apical end was identified and captured by the camera attached. The extent of linear dye penetration of all the images was estimated using ImageJ software. The data was analysed using a Kruskal-Wallis test with statistical package SPSS version 11.5.

\section{RESULTS}

Coronal leakages for canals obturated with Real Seal and AH plus with different moisture conditions are measured and data collected and subjected to statistical analysis. The data was analysed using a Kruskal-Wallis test with statistical package SPSS version 11.5.

The mean coronal leakage and standard deviation in each for each moisture condition and for each material are shown in the table 1. Group 5 (Gutta percha / Real Seal SE, paper point) showed the best result with the least coronal leakage (2.71 $\mathrm{mm}$ and $\mathrm{P}$ value 0.008 ) and Group 6 (GP/ Real Seal SE, moist canal) showed the highest leakage $(15.79 \mathrm{~mm})$. None of the experimental groups showed leak proof obturation (hermetic seal). Though all the groups showed some amount of coronal leakage, there was no statistical significance difference between GP / AH plus and GP / RS subjected to moisture condition I and II. However GP / Real Seal SE, paper point (Group 6) in moisture condition III was compared with other moisture conditions showed maximum leakage which was statistically highly with other groups as shown in table 1 . 
Table 1:

\begin{tabular}{|c|c|c|c|c|}
\hline Groups & Sample & Mean & Minimum & Maximum \\
\hline $\begin{array}{l}\text { 1. GP / AH plus } \\
\text { ethanol group }\end{array}$ & 5 & $\begin{array}{c}3.75 \\
\pm 2.18\end{array}$ & $1.76 \mathrm{~mm}$ & $6.28 \mathrm{~mm}$ \\
\hline $\begin{array}{l}\text { 2. GP / AH plus } \\
\text { paper point group }\end{array}$ & 5 & $\begin{array}{c}4.17 \\
\pm 1.59\end{array}$ & $2.65 \mathrm{~mm}$ & $6.39 \mathrm{~mm}$ \\
\hline $\begin{array}{l}\text { 3. GP / AH plus } \\
\text { moist canals }\end{array}$ & 5 & $\begin{array}{c}5.18 \\
\pm 3.76\end{array}$ & $3.75 \mathrm{~mm}$ & $12.20 \mathrm{~mm}$ \\
\hline $\begin{array}{l}\text { 4. GP / RS ethanol } \\
\text { group }\end{array}$ & 5 & $\begin{array}{c}3.28 \\
\pm 0.640\end{array}$ & $2.64 \mathrm{~mm}$ & $4.32 \mathrm{~mm}$ \\
\hline $\begin{array}{l}\text { 5.GP / RS paper } \\
\text { point group }\end{array}$ & 5 & $\begin{array}{c}2.71 \\
\pm 0.41\end{array}$ & $2.05 \mathrm{~mm}$ & $3.19 \mathrm{~mm}$ \\
\hline $\begin{array}{l}\text { 6. GP / RS moist } \\
\text { canal group }\end{array}$ & 5 & $\begin{array}{l}15.34 \\
\pm 0.53\end{array}$ & $15.79 \mathrm{~mm}$ & $17.00 \mathrm{~mm}$ \\
\hline
\end{tabular}

\section{DISCUSSION}

Coronal leakage of the root canal filled tooth is considered to be an important cause in the failure of the root canal treatment ${ }^{5}$. There have been numerous dye leakage, bacterial penetration, and fluid filtration leakage studies that have evaluated coronal leakage. Several studies have shown that root canal fillings are susceptible to leakage when contaminated coronally by artificial saliva and microorganisms $\mathrm{s}^{8-10}$. Hence the present study was conducted to evaluate the coronal leakage in canals obturated with Real Seal and AH plus.

Dye penetration studies have frequently been used for leakage evaluation ${ }^{16,17}$, in spite of the fact that their clinical significance has been questioned ${ }^{12,18}$. Nevertheless, previous studies revealed a good correlation between dye penetration and other leakage evaluation methods ${ }^{19,20}$. The results of this study demonstrated that the moisture condition of root canals at the time of obturation and the type of sealer that was used had a significant effect on micro leakage. All materials exhibited some amount of leakage. Bondable methacrylate resin-based sealers are better alternatives for root canal obturation than their nonbonding counterparts. This statement does not appear to be open handedly supported by the plethora of ex vivo studies. Group 5 (GP / Real Seal SE, paper point) showed the best result with the least coronal leakage. This could be most likely due to, the hydrophilicity of the sealer which allows the penetration of resin tags and the formation of a hybrid layer, resulting in micromechanical interlocking ${ }^{13,21}$. Similar results were obtained by Patel et $a l^{14}$ in root canals filled with Real Seal (Sybron Endo), a methacrylate-based sealer. The hydrophilic propensity of these resin-based materials can thus provide more thorough seal than the hydrophobic AH plus sealer. Leakage in root canals filled with GP / Real Seal SE, was significantly less in comparison with the other conditions, when using methacrylate-based resin sealers.

In condition I- ethanol was used to dry the canals, which showed less leakage than in the moist canals. There was no statistically significance between the teeth restored in Group 1 (GP / AH plus) and Group 4 (GP / RS SE). Moisture degree is one of the most important factors affecting Degree of Conversion (DC) of resin-based material. It was previously noted that water could inhibit polymerization of dentin bonding agents ${ }^{22}$. Wang and Spencer ${ }^{23}$ reported that DC of dentin adhesive dropped from $93 \%$ to $36 \%$ as water content increased from $20 \%$ to $60 \%$. In another study, Wan-Cui $\mathrm{Wu}^{24}$ demonstrated that root canal dried with paper points followed by $95 \%$ ethanol, which provided drier dentin, favored the DC of Real Seal SE. Recent study by Hosaka et $a l^{25}$ revealed that application of ethanol in hydrophilic resin bonding could increase the durability of resin-dentin bonds. It was speculated that ethanol might be able to remove excess water in dentin to prevent suboptimal polymerization of resin. Because suboptimal polymerization of resin represented sites of nano-leakage that decreased the durability of resindentin bonds, supplemental use of $95 \%$ ethanol in root canal drying might favor the bond between Real Seal SE and root dentin over time.

In condition II, Groups 2 (GP / AH Plus) and Group 5 (GP / RS) only paper points were used to dry the canals, resulting in a greater degree of dryness within the canals. This condition also showed significant differences with condition moist canals. Wong and Spencer ${ }^{23}$ demonstrated that dentinal tubules normally remain filled with water unless the canal is thoroughly dried. This condition was more desirable than a totally dry or totally wet canal but was probably not totally sufficient for maximum effective hydrophilic resin penetration. A prescribed amount of water could decrease the viscosity and help increase the degree of conversion of this water-compatible resin. Water is also an essential component to provide the medium for ionization of acidic monomers. In a report by Tay et $a l^{13}$ the presence of a hybrid layer and resin sealer tags as a result of dentin surface demineralization by EDTA in root canals filled with gutta-percha cones and EndoRez was demonstrated. These observations corresponded well with those of Osorio et $a l^{27}$, who showed that the collagen 
network of the dentin is better preserved after the use of EDTA as the final rinse. In the current study as well as in the clinical situation, one might expect a similar effect because EDTA was also used in our irrigation protocol. Root canals subjected to moisture condition III (Moist canals) in Groups 3 and 4 showed a higher degree of leakage. In Group 4, water has not completely displaced in spite of the hydrophilic properties of the epiphany sealers.

Self etch primers were developed based on the concept that dentin etching and priming could be accomplished simultaneously. The penetration and demineralization process neutralizes the acidic portions of the molecules. The presence of water within the resin and the continuous supply of water within the dentin/tubules might cause incomplete polymerization of the adhesive, i.e., these water-soluble monomers could be diluted to an extent that there might not be adequate free radicals for polymer chain propagation. The presence of residual water within the adhesive may lead to domains of incomplete polymerization of the adhesive or sequestrations of more hydrophilic oligomers in these particular regions ${ }^{26}$. Water permeation during the polymerization process might result in the entrapment of water droplets within the sealer-dentin interface. This might result in bond disruption and further increased leakage. Wong and Spencer ${ }^{23}$ also reported that excess water can inhibit polymerization of methacrylate-based resins. The present study is in agreement with the critical review done by Young Kyung $\mathrm{Kim}^{15}$ et al. in which they summarized the results of in vitro studies that compared the extent of leakage between teeth filled with methacrylate resinbased sealers versus conventional nonbonding sealers and showed the very narrow difference between the two materials.

\section{CONCLUSIONS}

GP with Real Seal SE Sealer showed better results than GP / AH plus sealer when the canals were dried with paper points. GP with Real Seal SE showed maximum dye leakage when the root canal was left moist. The objective of obturation of the root canal space is to create an impervious seal. Though the search for a material which provides such a hermetic seal continues, within the limits of this study we can conclude that the sealing abilities of GP / Real Seal SE are better than GP / AH plus sealer, when canals are dry.

\section{REFERENCES}

1. Schilder H. Filling root canals in three dimensions. DCNA. 1967; 11: 723-44.

2. Gutmann JL. Clinical radiographic and histologic perspectives on success and failure in endodontics. DCNA. 1992; 36: 379-92.

3. Tay FR, Loushine RJ, Lambrechts P, Weller RN, Pashley DH. Geometric factors affecting dentine bonding in root canals: A theoretical modeling approach. J Endod. 2005; 31: 584-9.

4. Wang CS, Debelian GJ, Teixeira FB. Effect of intracanal medicament on the sealing ability of root canals filled with Resilon. J Endod. 2006; 32: 532-6.

5. Stratton RK, Apicella MJ, Mines P. A fluid filtration comparison of gutta-percha versus Resilon, a new soft resin endodontic obturation system. $J$ Endod. 2006; 32: 642-5.

6. Tunga U, Bodrumlu E. Assessment of the sealing ability of a new root canal obturation material. $J$ Endod. 2006; 32: 876-8.

7. Saunders WP, Saunders EM Coronal leakage as a cause of failure in the root canal therapy. Endod Dent Tramatol. 1994; 10: 105-108.

8. Swanson K, Madison S. An evaluation of coronal micro leakage in endodontically treated teeth. Part 1. Time periods. J Endod. 1987; 13: 56-9.

9. Madison S, Wilcox LR. An evaluation of coronal micro leakage in endodontically treated teeth. Part III. In vivo study. J Endod. 1988; 14: 455-8.

10. Torabinejad M, Ung B, Kettering JD. In vitro bacterial penetration of coronally unsealed endodontically treated teeth. J Endod. 1990; 16: 566-9.

11. Ray HA, Trope M. Periapical status of endodontically treated teeth in relation to the technical quality of the root filling and the coronal restoration. Int Endod J. 1995; $28: 12-8$.

12. Wu MK, Fan B, Wesselink PR. Diminished leakage along root canals filled with gutta-percha without sealer over time: A laboratory study. Int Endod J. 2000; 33: 121-5.

13. Tay FR, Loushine RJ, Weller RN, et al. Ultrastructural evaluation of the apical seal in roots filled with a 
polycaprolactone-based root canal filling material. $J$ Endod. 2005; 31: 514-9

14. Patel DV, Sherriff M, Ford TRP, Watson TF, Mannocci F. The penetration of Real Seal primer and Tubliseal into root canal dentinal tubules: a confocal microscopic study. Int Endod J. 2007; 40: 67-71.

15. Young Kyung Kim, Sui Mai The Self-etching Potential of Real Seal Versus Real Seal SE. J Endod. 2009; 35:1264-1269.

16. Scott AC, Vire DE, Swanson R. An evaluation of the Thermafil endodontic obturation technique. J Endod. 1992; 18: 340-3.

17. Ahlberg KM, Assavanop P, Tay WM. A comparison of the apical dye penetration patterns shown by methylene blue and India ink in root filled teeth. Int Endod J. 1995; 28: 30-4.

18. Oliver CM, Abbott PV. Correlation between clinical success and apical dye penetration. Int Endod J. 2001; 34: 637-44.

19. Delivanis PD, Chapman KA. Comparison and reliability of techniques for measuring leakage and marginal penetration. Oral Surg Oral Med Oral Pathol. 1982; 53: 410-6.

20. Martell B, Chandler NP. Electrical and dye leakage comparison of three root-end restorative materials.
Quintess Int. 2002; 33: 30-4.

21. Tay FR, Loushine RJ, Monticelli F, et al. Effectiveness of resin-coated gutta-percha cones and a dual-cured, hydrophilic methacrylate-based sealer in obturating root canals. J Endod. 2005; 31: 659-64.

22. Jacobsen T, So“ derholm KJ. Some effects of water on dentin bonding. Dent Mater. 1995; 11: 132-6.

23. Wang Y, Spencer P. Continuing etching of an all-in-one adhesive in wet dentin tubules. J Dent Res. 2005; 84: 350-4.

24. Wan-Cui $\mathrm{Wu}$, Deepti Shrestha, et al. Degree of conversion of a methacrylate-based endodontic sealer: A Micro-raman spectroscopic study. J Endod. 2010; 2: 329-333.

25. Hosaka K, Nishitani Y, Tagami J, et al. Durability of resin-dentin bonds to water- vs ethanol-saturated dentin. J Dent Res. 2009; 88: 146-51.

26. Tay FR, Pashley DH, Yoshiyama M. Two modes of nanoleakage expression in single step adhesives. $J$ Dent Res. 2002; 81:472-6.

27. Osorio R, Erhardt MCG, Pimenta LAF, Osorio E, Toledano M. EDTA treatment improves resin-dentin bonds' resistance to degradation.J Dent Res. 2005; 84: 736-40. 